\title{
Tailings transport on high yield stress requirements: turbulent or laminar flow?
}

\author{
R Yánez Golder Associates S.A., Chile \\ C Tapia Golder Associates S.A., Chile
}

\begin{abstract}
In the mining industry, especially in Chile, tailings impoundment projects are tending to update their thickening technology or improve beach slopes due to environmental concerns, water scarcity, capacity restriction or economic variables.
\end{abstract}

Projects in Chile either being designed or in operation under the concept of high-density tailings do not exceed a yield stress (fully sheared) of approximately 40-50 Pa, and their tailings transport systems may operate in turbulent regimes.

There are currently significant research and development projects to improve thickening technology, impoundment deposition strategies and beach slopes management. However, do we have sufficient information and criteria relating to the long distance and large pipeline diameter for the transportation of tailings between the thickening and deposition points for high yield stress requirements?

What happens to the transportation of tailings if it must be designed under the concept of high density with a yield stress (fully sheared) above 40-50 Pa but still cannot be considered a paste tailings?

Can we expend efforts in thickening and depositing if we do not adequately handle what happens in between (transport)?

Generally, for high-density tailings, transportation is designed to operate under the concept of turbulent flow. However, at yield stress above 40-50 Pa, turbulent flow will mean excessive internal wear on the pipelines, due to high velocities and a significant energy demand.

What should the criteria be that govern the tailings transport for the high-density zone above 40-50 Pa? Design under turbulent regime or laminar regime?

The paper will present an analysis of studies developed to date, identifying and evaluating the variables that govern the design of high-density transport systems within the proposed yield stress ranges.

A technical and economic case will be evaluated for a tailings transport project on the proposed yield stress ranges, showing the differences that may exist based on the assumed criteria.

The criteria and results of the analysis will be presented in this paper.

Keywords: tailings transport, high-density tailings, turbulent regime, laminar regime

\section{Introduction}

Considering the thickened tailings transport, and the differences in design criteria according to several studies developed by universities and consultancies, the importance in defining the main factors that affect tailings transportation increases every day.

Several studies focus on the yield stress, weight concentration and head losses. However, the practical considerations overestimate the theoretical values, resulting in oversized equipment. 
For that reason, a study analysing tailings transportation under high yield stress has been developed to identify the main costs involved in such projects and simplifying the project's parameters, but first of all delimiting a main question - do we transport the tailings at turbulent or laminar flow?

This important question should be addressed at the beginning of every project of this kind, taking into account the impact on throughput, distance, power availability, etc.

If we have the freedom to choose one regime or another, which one should we consider?

This study uses a theoretical case study with a high throughput of 100,000 tonnes per day (tpd) and a relatively short distance for transporting the thickened tailings $(2,000 \mathrm{~m})$. The objective is to determine the practicality of laminar or turbulent flow, when the thickened tailings is at $67 \%$ solids concentration per weight $\left(C_{w}\right)$ has a high yield stress (fully sheared) fluctuating between 40 and $70 \mathrm{~Pa}$.

A conceptual CAPEX and OPEX were developed, and the results show the main differences for each system, sufficient for decision-making.

\section{Scenario description}

The scenario analysed considered a tailings pumping system of 2,000 $\mathrm{m}$ for a high-density tailings transportation between 40 and 70 Pa fully sheared. Parameters used for the analysis are described in Table 1.

Table 1 Scenario parameters

\begin{tabular}{lll}
\hline Parameter & Unit & Value \\
\hline Nominal solids concentration per weight $\left(C_{\mathrm{w}}\right)$ & $\%$ & 67 \\
Years operating & Year & 10 \\
Tailings rate & $\mathrm{tpd}$ & 100,000 \\
Specific gravity & - & 2.70 \\
Tailings density & $\mathrm{t} / \mathrm{m}^{3}$ & 1.73 \\
Yield stress (fully sheared) & $\mathrm{Pa}$ & $40-70$ \\
Plastic viscosity & $\mathrm{Pa} . \mathrm{s}$ & $0.1-0.25$ \\
$\mathrm{D}_{50}$ & $\mu \mathrm{m}$ & 65 \\
$\mathrm{D}_{85}$ & $\mu \mathrm{m}$ & 180 \\
\hline
\end{tabular}

\section{Flow regime analysis}

According to the scenario described for a tailings production of 100,000 tpd and a yield stress range between 40 and $70 \mathrm{~Pa}$, the transition velocity was determined using the laminar/turbulent transition model proposed by Slatter and Wasp (2000).

The study proposes a relationship between the Hedström ( $\mathrm{He}$ ) number and a critical Reynolds number (Rec) in order to develop a simple power law relationship between the Rec and He to predict critical flow behaviour.

$$
\begin{aligned}
\operatorname{Re} & =\frac{\rho \vee D}{K} \\
\operatorname{Rec} & =\frac{\rho V c D}{K} \\
\mathrm{He} & =\frac{D^{2} \rho \tau_{\mathrm{y}}}{\mathrm{K}^{2}}
\end{aligned}
$$


where:

$$
\begin{aligned}
& \rho \quad=\text { fluid density. } \\
& \mathrm{V} \quad=\text { average velocity. } \\
& \mathrm{V}_{\mathrm{c}} \quad=\text { critical velocity. } \\
& \mathrm{D} \quad=\text { internal pipe diameter. } \\
& \mathrm{K} \quad=\text { plastic viscosity. } \\
& \tau_{\mathrm{y}} \quad=\text { yield stress. }
\end{aligned}
$$

According to the parameters described in Table 1, the correlation is defined as high range and is formulated as follows:

$\operatorname{Rec}=26 \mathrm{He}^{0.5}$ for $\mathrm{He}>1.5 \times 10^{5}$

$$
\mathrm{V}_{\mathrm{c}}=26 \sqrt{\frac{\tau_{\mathrm{y}}}{\rho}}
$$

The deposition velocity was determined based on work presented by Wilson et al. (2010).

Figure 1 shows the results of the transition velocity between 3.5 and $4.6 \mathrm{~m} / \mathrm{s}$ for $40-70 \mathrm{~Pa}$, respectively.

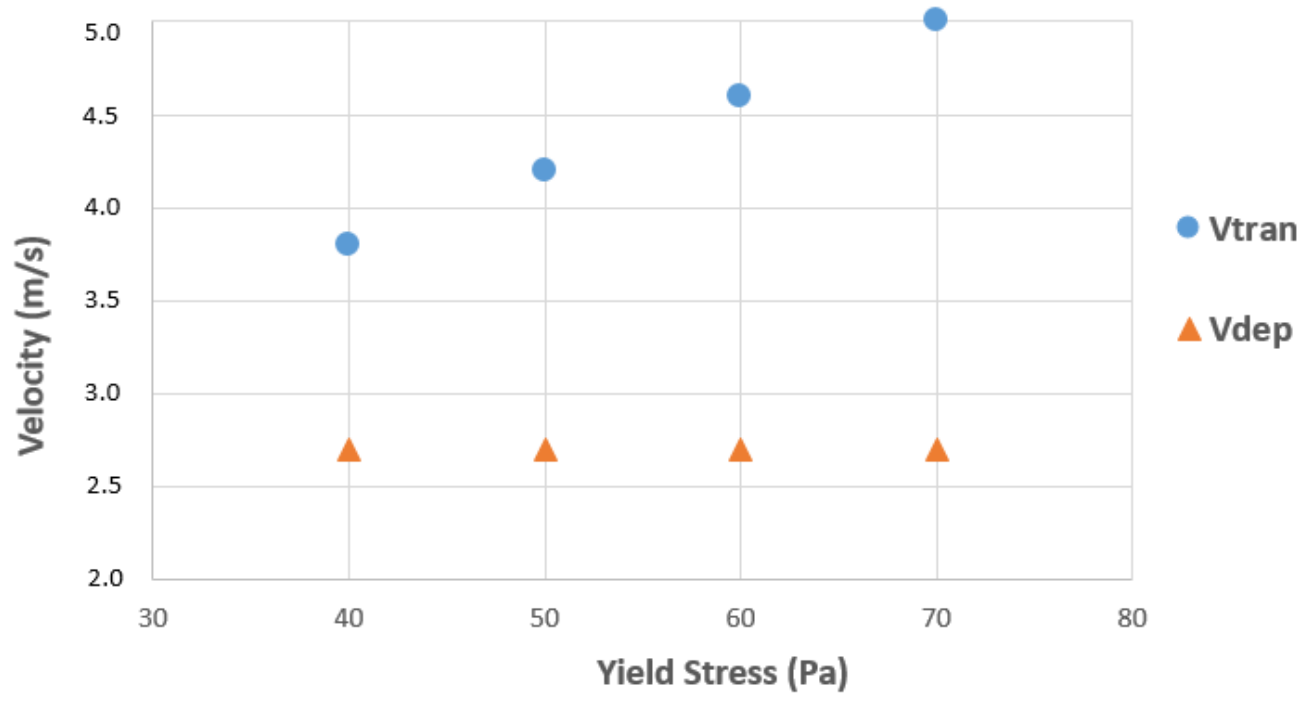

Figure 1 Transition velocity for different yield stresses

According to Figure 1, the question that arises for the design of a high-density tailings transport system is: what is the optimal velocity for the nominal pipeline diameter of the system? Also, does one design the system for high velocities in order to ensure a turbulent regime or design with lower velocities considering a laminar regime?

If the nominal flow is considered under a laminar regime, what is the optimum velocity for the tailings transport; below 10,20 or $50 \%$ of the transition velocity?

The friction losses, considering a Bingham plastic flow, were calculated for a laminar regime using the Buckingham model as per a simplified equation from the analysis developed by Govier and Aziz (1972) and, for a turbulent regime, the Wilson and Thomas (1985) model.

Figure 2 resumes an analysis of the friction losses for different velocities for the same tailings rate, modifying the pipeline diameters, according to the yield stress and transition velocity described in Figure 1. 


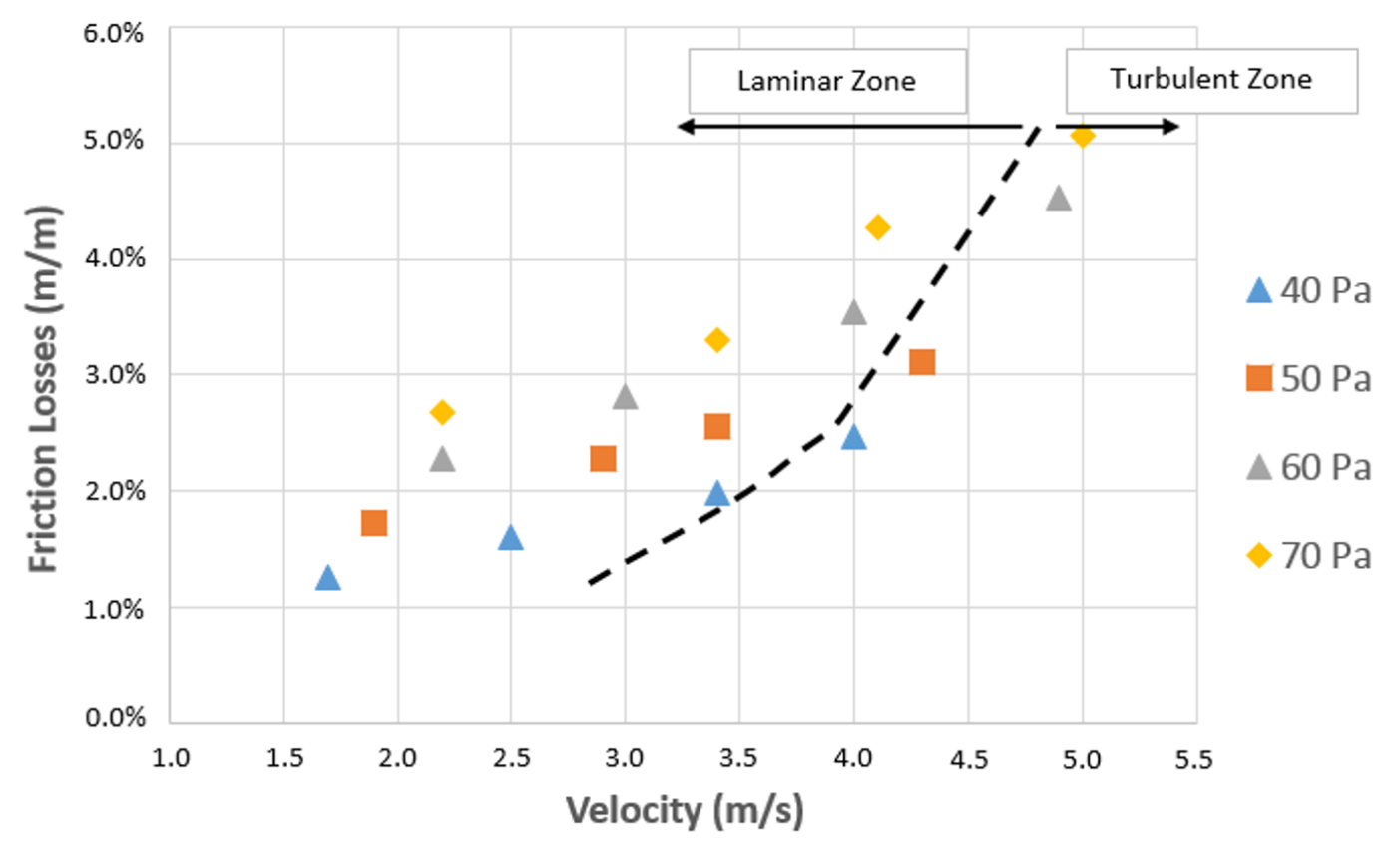

Figure 2 Friction losses for laminar and turbulent flows

Tables 2 to 5 show the diameters used for the friction losses described in Figure 2.

Table 2 Pipeline considered for $40 \mathrm{~Pa}$

\begin{tabular}{llllll}
\hline Yield stress (Pa) & Tonnage (tpd) & Velocity $(\mathrm{m} / \mathrm{s})$ & J (\%) & Pipeline & Regime \\
\hline 40 & 100,000 & 4.0 & 2.5 & $24^{\prime \prime}(622 \mathrm{~mm})$ sch std & Turbulent \\
40 & 100,000 & 3.4 & 2.0 & $26^{\prime \prime}(660 \mathrm{~mm})$ sch std & Laminar \\
40 & 100,000 & 2.5 & 1.6 & $30^{\prime \prime}(762 \mathrm{~mm})$ sch std & Laminar \\
40 & 100,000 & 1.7 & 1.3 & $36^{\prime \prime}(812 \mathrm{~mm})$ sch std & Laminar \\
\hline
\end{tabular}

Table 3 Pipeline considered for $50 \mathrm{~Pa}$

\begin{tabular}{llllll}
\hline Yield stress (Pa) & Tonnage (tpd) & Velocity $(\mathrm{m} / \mathrm{s})$ & J (\%) & Pipeline & Regime \\
\hline 50 & 100,000 & 4.3 & 3.1 & $24^{\prime \prime}(622 \mathrm{~mm})$ sch 40 & Turbulent \\
50 & 100,000 & 3.4 & 2.6 & $26^{\prime \prime}(660 \mathrm{~mm})$ sch std & Laminar \\
50 & 100,000 & 2.9 & 2.3 & $28^{\prime \prime}(711 \mathrm{~mm})$ sch std & Laminar \\
50 & 100,000 & 1.9 & 1.7 & $34^{\prime \prime}(863 \mathrm{~mm})$ sch std & Laminar \\
\hline
\end{tabular}

Table 4 Pipeline considered for $60 \mathrm{~Pa}$

\begin{tabular}{llllll}
\hline Yield stress (Pa) & Tonnage (tpd) & Velocity $(\mathrm{m} / \mathbf{s})$ & J (\%) & Pipeline & Regime \\
\hline 60 & 100,000 & 4.9 & 4.5 & $22^{\prime \prime}(559 \mathrm{~mm})$ sch std & Turbulent \\
60 & 100,000 & 4.0 & 3.5 & $24^{\prime \prime}(622 \mathrm{~mm})$ sch std & Laminar \\
60 & 100,000 & 3.0 & 2.8 & $28^{\prime \prime}(711 \mathrm{~mm})$ sch xs & Laminar \\
60 & 100,000 & 2.2 & 2.3 & $32^{\prime \prime}(813 \mathrm{~mm})$ sch std & Laminar \\
\hline
\end{tabular}


Table 5 Pipeline considered for $70 \mathrm{~Pa}$

\begin{tabular}{llllll}
\hline Yield stress (Pa) & Tonnage (tpd) & Velocity $(\mathrm{m} / \mathrm{s})$ & J (\%) & Pipeline & Regime \\
\hline 70 & 100,000 & 5.2 & 5.5 & $22^{\prime \prime}(559 \mathrm{~mm})$ sch 60 & Turbulent \\
70 & 100,000 & 3.9 & 4.1 & $24^{\prime \prime}(622 \mathrm{~mm})$ sch std & Laminar \\
70 & 100,000 & 3.3 & 3.6 & $26^{\prime \prime}(669 \mathrm{~mm})$ sch std & Laminar \\
70 & 100,000 & 2.8 & 3.2 & $32^{\prime \prime}(813 \mathrm{~mm})$ sch std & Laminar \\
\hline
\end{tabular}

In practice, if the nominal pipeline diameter was designed for a nominal flow, it has been designed to work under a laminar regime. The average velocity will not be enough to keep the particles moving and a stationary tailings bed will begin to form on the bottom of the pipeline.

This bed, as it grows without control, will result in a decrease in the width of that section of pipeline and will cause a possible blockage, thus stopping the tailings operation.

The first alternative that should be considered is to design the nominal diameter of the pipeline to ensure a turbulent regime and to avoid a laminar regime.

A second alternative (Figure 3 ), is to design the nominal diameter $\left(D_{1}\right)$ for a laminar regime accepting segregation in the pipeline and to define an appropriate diameter $\left(D_{2}\right)$ that can re-develop a turbulent regime, re-mobilise the deposited particles and return to its original design $\left(D_{1}\right)$, developing a cycle during the tailings transportation between diameters $D_{1}$ and $D_{2}$.

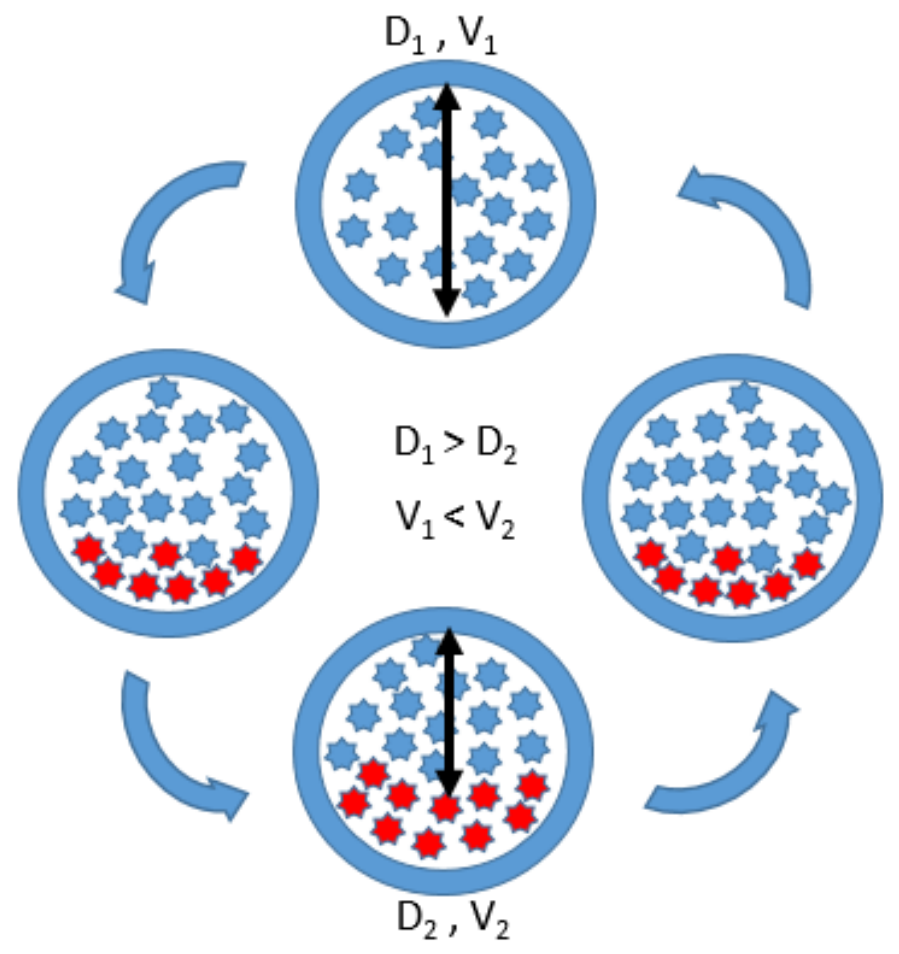

Figure 3 Pipeline diameter and velocity

The power requirements for a possible pumping station and the admissible pipe pressures must be checked for both diameters.

A cost estimate analysis will be developed in Section 5 to identify if there are benefits of both alternatives.

For the transport of tailings in large-diameter, long-distance pipelines in some operations in the north of Chile, due to the deposition plan of the tailings impoundment, multiple discharges operating simultaneously in the pipeline are used. Tailings flow in the pipeline decreases, and the velocity decreases along the pipeline, 
thus reaching velocities in the last section of the pipeline below the transition zone, therefore operating in a laminar regime and causing a bed in the pipeline (Figure 4).

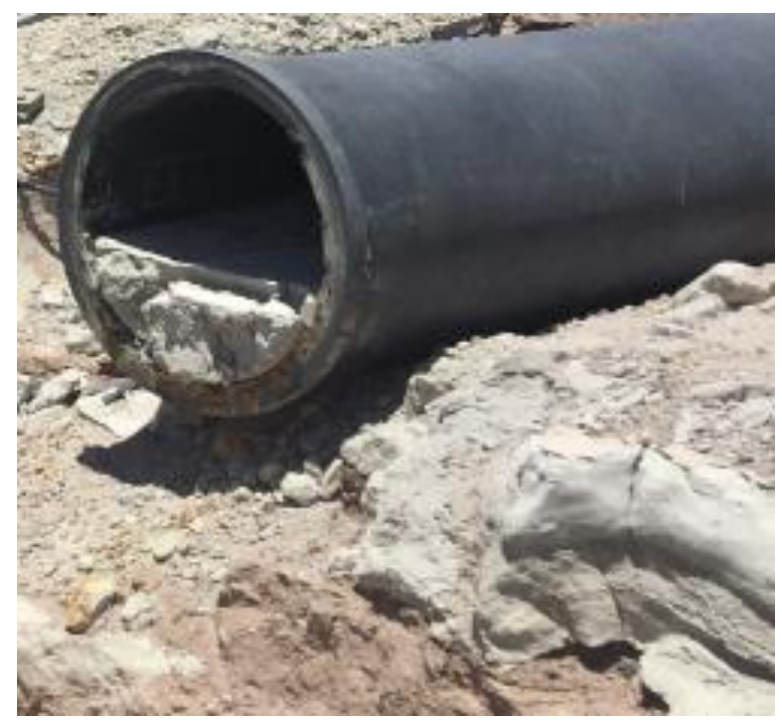

Figure 4 Tailings bed in the pipeline

To remove this tailings bed, the operators close all the intermediate discharges, leaving only the final discharge open, thus increasing the flow in the pipeline and consequently its velocity, therefore developing a turbulent regime in the pipeline and removing the formed bed.

\section{$4 \quad$ Selected alternatives}

Four alternatives were selected for the analysis according to the parameters defined in Table 1. Different nominal diameters, for the same tailings tonnage $(100,000 \mathrm{tpd})$, present nominal velocities in the turbulent and laminar regimes.

The worst case alternative for transition velocity is defined as $70 \mathrm{~Pa}$ (Table 5). The analysis shows that for a pipeline diameter of $559 \mathrm{~mm}$, the nominal velocity of the tailings transportation will be above the transition velocity, thus maintaining a turbulent regime and avoiding a bed formation in the pipeline.

The analysis of the $559 \mathrm{~mm}$ pipeline shows that $0.95 \mathrm{kPa} / \mathrm{m}$ of power will be enough to ensure, in the worst case scenario of $70 \mathrm{~Pa}$, a turbulent flow in the system (Figure 5).

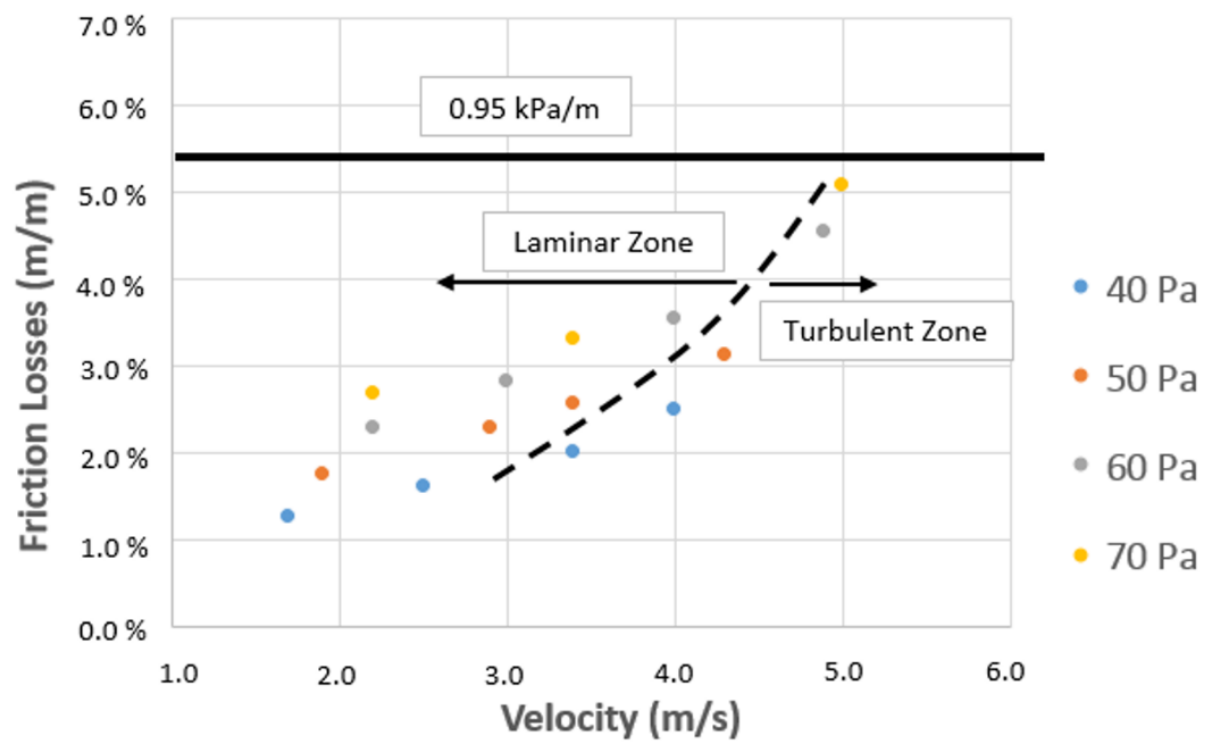

Figure 5 Friction losses for $0.95 \mathrm{kPa} / \mathrm{m}$ 
According to above and as defined in Table 5, for the pipeline diameters of 622,669 and $813 \mathrm{~mm}$, the nominal velocity for a nominal tonnage of $100,000 \mathrm{tpd}$ will be under the transition velocity and is defined as a laminar regime. However, the power installed for the system $(0.95 \mathrm{kPa} / \mathrm{m})$ was considered, as the nominal internal diameter $\left(D_{2}\right.$, Figure 3$)$ will be $559 \mathrm{~mm}$ in order to ensure a turbulent flow as the tailings bed in the pipeline increases.

\section{$5 \quad$ Cost estimate}

The scenario studied considered a tailings transportation system of 2,000 $\mathrm{m}$ with a field slope of $0.5 \%$ (Figure 6). The four pipeline alternatives were analysed using the same pumping station as described in Section 4.

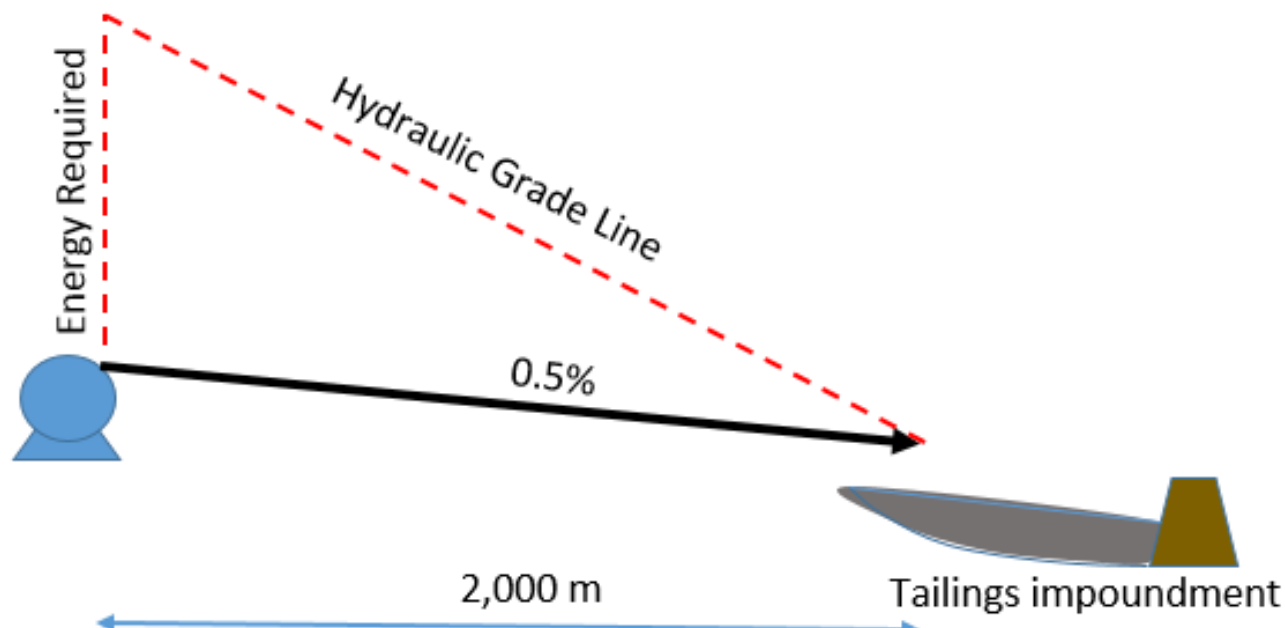

Figure 6 Scenario description

For the pumping analysis, the same pump efficiency and solid correction factor were used for the worst case scenario of $70 \mathrm{~Pa}$ (Table 6).

For the pipeline wear rate in turbulent flow, values were considered from empirical tailings experiences in Chile. For the pipeline wear rate in laminar flow, values were considered according to the double layer model. The wear rate is related to the drag forces between the tailings and the pipeline wall. The magnitude must be determined case by case (not the purpose of this paper, but important), and there is not a linear relation in the magnitude order with the turbulent regime.

To determine the cost estimation of a tailings transport system, Table 6 presents the material cost criteria that have been assumed for pipelines, pumps and motors.

Table 6 Capex assumptions

\begin{tabular}{lll}
\hline Description & Unit & Cost per unit \\
\hline Pump distance & $\mathrm{m}$ & 2,000 \\
Slope available on field & $\%$ & 0.5 \\
Pump efficiency & $\%$ & 80 \\
Solid correction factor & - & 0.85 \\
Motor efficiency & $\%$ & 95 \\
Pump and motor & USD/hp & 400 \\
Carbon steel pipeline & USD/m & $1,000-2,700$ \\
Pump efficiency & $\%$ & 75 \\
\hline
\end{tabular}


To determine the operational and maintenance cost, Table 7 shows the considerations for all alternatives.

Table 7 Operational and maintenance evaluation

\begin{tabular}{lll}
\hline Description & Unit & Cost per unit \\
\hline Operating time & h/year & 7,880 \\
Energy cost & USD $/ \mathrm{kW}$ & 0.12 \\
Interest rate & Rate to actualise future costs & $8 \%$ \\
Abrasion rate for flow velocity: & & \\
$3.5(\mathrm{~m} / \mathrm{s})$ & & 1.3 \\
$4.0(\mathrm{~m} / \mathrm{s})$ & $\mathrm{mm} /$ year & 1.6 \\
$5.0(\mathrm{~m} / \mathrm{s})$ & & 5.0 \\
\hline
\end{tabular}

Figure 7 shows the results of the analysis. The capital cost, as all alternatives were based on the same pumping system, rises mainly due to the increase in pipeline diameter.

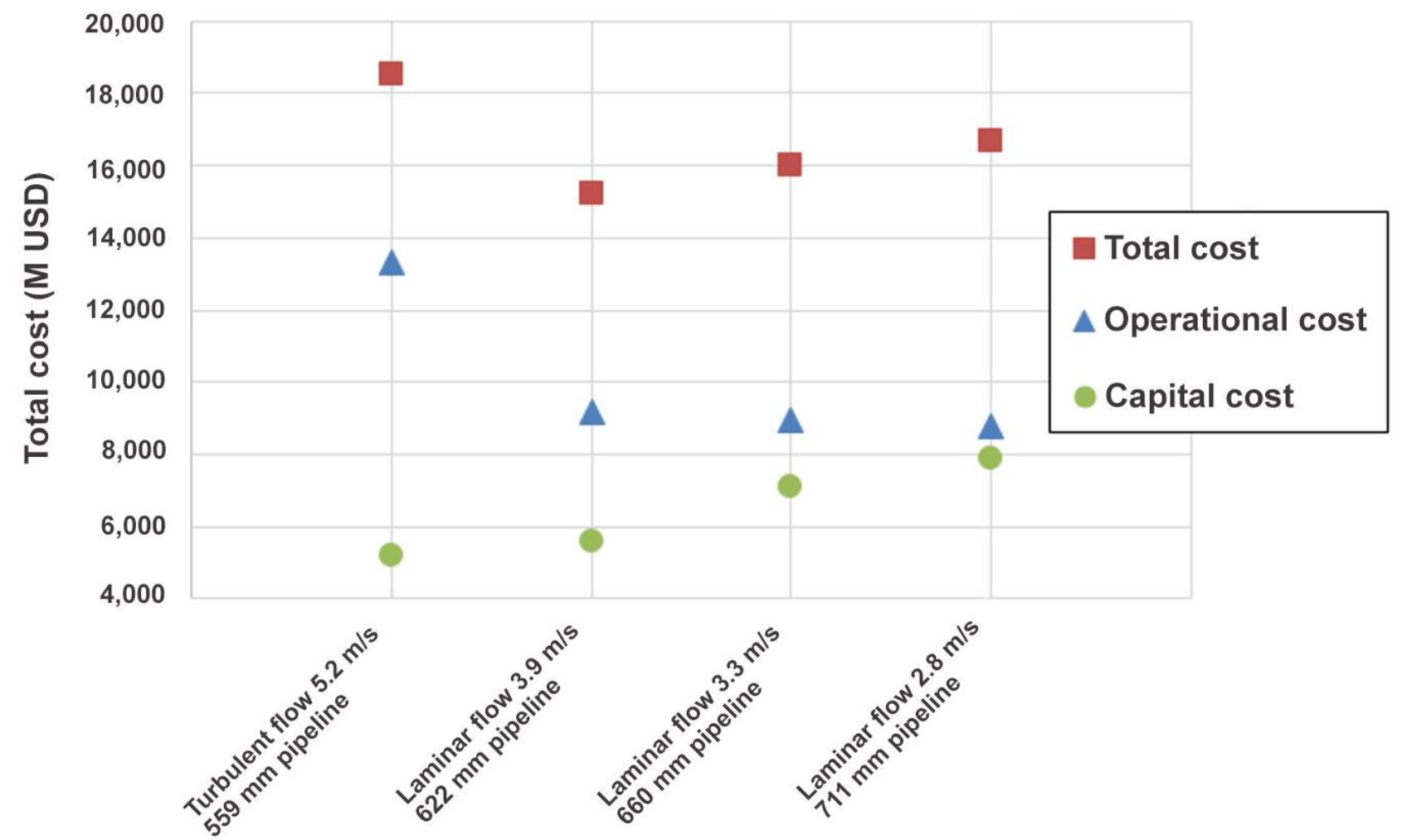

Figure 7 Cost estimate for alternatives

The operational cost lessens as the nominal velocity selected decreases, meaning less energy consumption and less pipeline wear.

However, the total cost does not decrease linearly as may be expected. The lower total cost was obtained for the second alternative of $622 \mathrm{~mm}$ pipeline. 


\section{Conclusion}

For the tonnage and yield stress evaluated, pipeline diameters were considered between 559-711 mm. According to friction losses and transition velocity, a minimum gradient of $0.95 \mathrm{kPa} / \mathrm{m}$ is sufficient for pumping power if a turbulent flow is required.

The cost estimate evaluation indicates that the lowest cost is the laminar regime alternative, with a $622 \mathrm{~mm}$ diameter pipeline considering a $0.95 \mathrm{kPa} / \mathrm{m}$ pumping system.

A combination between a system that ensures a turbulent flow but that can nominally operate at a laminar flow is seen as an alternative to be developed.

It is recommended to analyse the double layer model considering drag forces to determine the wear rate from laminar flow, so that the present analysis can be more accurate with OPEX considerations taken into account.

\section{References}

Govier, GW \& Aziz, K 1972, The Flow of Complex Mixtures in Pipes, Van Nostrand Reinhold, New York.

Slatter, PT \& Wasp, EJ 2000, 'The laminar/turbulent transition in large pipes', in J Sabota (ed.), Proceedings of the 10th International Conference on Transport and Sedimentation of Solid Particles, BHR Group, Cranfield, pp. 389-399.

Wilson, KC, Addie, GR, Sellgren, A \& Clift, R 2010, Slurry Transport Using Centrifugal Pumps, Springer Publishing, New York.

Wilson, KC \& Thomas, AD 1985, 'A new analysis of the turbulent flow of non-newtonian liquids', The Canadian Journal of Chemical Engineering, vol. 63, no. 4, pp. 539-546. 
